\title{
SOSIAL MEDIA SEBAGAI SARANA KREASI DAN EKSPRESI KARYA SENI RUPA DAN DESAIN
}

\author{
I G. A. A. Widiari Widyaswari' ${ }^{1}$ I G. N. Widnyana ${ }^{2}$ \\ 'Prodi Desain Komunikasi Visual, Sekolah Tinggi Desain Bali, Denpasar, Bali, Indonesia \\ ${ }^{2}$ Prodi Desain Komunikasi Visual, Fakultas Bahasa dan Seni, Universitas Pendidikan Ganesha, Singaraja, Bali, Indonesia \\ e-mail: widiariwidyaswari@std-bali.ac.id
}

\begin{abstract}
Social media is a medium of communication and information accessed through internet connection that is widely used by the community every day. Many use social media to interact with people in long distances so there is no need to meet in person. Social media originally present as a medium of communication and information and is now developed as a container for creative and expression through artwork and design created. With the development of social media in the digital era is certainly following the developments of existing features in social media. It is important to be noticed by the performers of art and design in order to be able to utilize the features of social media well so that it can steal the public's interest with all creativity displayed. Thus it can be concluded that social media plays an important role in the era of digital technology today with the many uses of social media as a means of creating and expressing artwork.
\end{abstract}

Keywords: social media, art and design, creations, expressions

\begin{abstract}
ABSTRAK
Sosial media merupakan media komunikasi dan informasi yang diakses melalui sambungan internet yang banyak digunakan oleh masyarakat setiap harinya. Banyak yang menggunakan sosial media untuk berinteraksi dengan orang-orang dalam jarak jauh sehingga tidak perlu bertemu secara langsung. Sosial media awalnya hadir sebagai media komunikasi dan informasi dan kini berkembang sebagai wadah untuk berkreasi dan berekspresi melalui karya seni dan desain yang diciptakan. Dengan berkembangnya sosial media di era digital ini tentunya mengikuti dengan perkembangan-perkembangan fitur yang ada dalam sosial media. Hal tersebut penting untuk diperhatikan oleh pelaku seni dan desain agar mampu memanfaatkan fitur-fitur sosial media dengan baik sehingga bisa mencuri perhatian publik dengan segala kreativitas yang ditampilkan. Dengan demikian dapat disimpulkan bahwa sosial media memegang peranan penting di era teknologi digital saat ini dengan banyaknya pemanfaatan sosial media sebagai sarana berkreasi dan mengekspresikan karya seni.
\end{abstract}

Kata kunci : sosial media, seni rupa dan desain, kreasi, ekspresi.

\section{PENDAHULUAN}

Memasuki era digital, banyak hal yang bisa membuat hidup lebih mudah. Seperti halnya bertemu orang baru, bersosialisasi, berbelanja, bahkan menyelesaikan pekerjaan hanya melalui media digital. Dengan berkembangnya media digital, tentunya diikuti dengan perkembangan jejaring sosial. Melalui jejaring sosial, atau yang biasa disebut sosial media maka orang-orang lebih mudah dalam menyelesaikan pekerjaan, mendapatkan informasi terkini yang bahkan menggeser keberadaan surat kabar sebagai media informasi selama ini. Sosial media merupakan suatu wadah atau wahana interaksi antar sesama pengguna secara tidak langsung melalui internet. Awalnya sosial media bertujuan untuk menjalin komunikasi, berbagi informasi, serta sebagai ajang menambah pertemanan. Tetapi kini 
perkembangannya tidak hanya sebatas pergaulan sosial, bahkan sebagai media promosi dan branding. Perkembangan sosial media begitu signifikan dari tahun ke tahun.

Awal mula sosial media dikenal sudah ada sejak tahun 1978. Media sosial yang dibuat bernama Bulletin Board System $(B B S)$ atau papan buletin, yang dibuat oleh Word Christensen dan Randy Suess. Kegunaannya adalah untuk berhubungan dengan orang lain menggunakan surat elektronik dan mengunggah (upload) serta mengunduh (download) menggunakan perangkat lunak (software) yang ada pada masa itu. Pada masa itu penggunaan internet masih melalui media telepon yang dihubungkan ke modem. Banyak sosial media bermunculan sejak tahun 1984 yaitu dimulai dengan munculnya Prodigy yaitu sebuah jasa hosting web dan menjual serta mengkoneksikan dial-up ke World Wide Web. Hingga awal tahun 90-an, mulai muncul beberapa situs yang menawarkan jejaring sosial seperti misalnya Sixdegree.com, Classmate.com, dan pada tahun 1999 muncul sebuah situs yang menawarkan penggunanya untuk bisa membuat halaman pribadinya yang bisa memuat hal apapun, sehingga dapat dikatakan blogger ini merupakan tonggak berkembangnya sosial media. Keberadaan sosial media mulai fenomenal sejak berdirinya Friendster di tahun 2002 diikuti dengan munculnya MySpace pada tahun 2003 serta LinkedIn yang juga berguna untuk mencari pekerjaan, sehingga fungsi dari sosial media pun mulai berkembang. Seiring dengan berjalannya waktu, muncullah jejaring sosial bernama Facebook pada tahun 2004 dan menggeser kepopuleran MySpace dan Friendster. Kelebihan dari Facebook sendiri adalah bisa menulis tulisan terkini atau status pembaharuan yang bisa digunakan oleh setiap pengguna Facebook. Perlahan pengguna Friendster dan My Space pun mulai beralih ke Facebook dikarenakan tampilannya yang semakin modern.

Setahun setelah kemunculan $\mathrm{Fa}$ cebook mulailah Youtube hadir untuk memberikan fasilitas ke penggunanya untuk menonton, mengunggah, atau berbagi video. Banyak sekali sosial media yang muncul pada tahun 2000-an dengan banyak fasilitas yang diberikan sehingga banyak yang ingin mencoba bahkan beralih ke setiap sosial media yang baru. Seperti misalnya Twitter, Google+, Instagram maupun Wizer yang tentunya pernah dicicipi oleh setiap pengguna aktif sosial media. Semakin meningkatkan fitur dan inovasi perkembangan teknologi, sosial media telah menjadi bagian dari gaya hidup masa kini, dengan berbagai keunggulan dan karakter yang berbeda dianggap mampu membantu kehidupan masyarakat.

Sosial media sudah menjadi konsumsi masyarakat sehari-hari, tidak hanya sebagai media interaksi bahkan sudah pada fungsi bisnis. Media sosial bisa dijadikan media jualbeli, media promosi, media beriklan maupun branding. Hingga awal tahun 2018 tercatat beberapa sosial media yang masih aktif digunakan oleh masyarakat, seperti Facebook, Twitter, Instagram dan Youtube. Sosial media juga banyak yang digunakan sebagai media untuk menyalurkan hobi. Orang-orang mendapatkan kepuasan tersendiri setelah berhasil menyalurkan hobi mereka melalui sosial media, terlebih lagi apabila mendapatkan respon dari orang lain. Tentunya hal-hal yang dibagikan dalam sosial media bisa menjadi suatu informasi baru bagi orang-orang yang belum mengetahui atau bagi orang-orang yang tertarik dan memiliki minat maupun hobi yang sama.

Meskipun sosial media memberikan kemudahan dan memperbaharui fiturnya secara berkala, tidak semua orang mampu memanfaatkannya sebagai sarana untuk berkreasi dan berekspresi. Beberapa konten yang akan diunggah ke sosial media tentunya harus mampu menarik perhatian audiens, sehingga nantinya mampu membuat interaksi hingga akhirnya dikenal oleh banyak orang. Membuat konten yang baik dan mampu menarik audiens tentunya tidak lepas dari ilmu periklanan dan branding. Terdapat hal-hal penting yang mempengaruhi keberhasilan suatu konten yang diunggah, seperti hal nya foto, warna, kualitas gambar, bahkan copywriting. Bagi orang yang 
menggunakan Facebook dan Instagram sebagai media branding-nya biasanya bermain di foto atau gambar, serta caption yang menarik. Sedangkan bagi yang menggunakan Youtube tentunya sangat memperhatikan kualitas video yang diunggah, cara pengambilan, serta pencahayaan. Hal-hal penting seperti itu tentunya sangat berpengaruh terhadap konten maupun orang yang mengerjakan projek tersebut.

\section{METODE PENELITIAN}

Penelitian ini menggunakan pendekatan eksploratif deskriptif, dimana data dikumpulkan untuk melihat keadaan nyata yang terjadi sekarang. Data yang didapatkan berdasarkan pengumpulan data primer yakni wawancara beberapa orang yang menggunakan sosial media untuk berkreasi dan mengekspresikan karyanya melalui sosial media, serta data sekunder berupa artikel, berita, serta hasil dari beberapa lembaga riset sehingga antara satu sumber dengan yang lain dapat dikaitkan dengan hasil dari wawancara dan observasi langsung sebagai pengguna sosial media.

\section{HASIL DAN PEMBAHASAN}

\section{Hasil}

Perkembangan sosial media yang selalu diikuti dengan pembaharuan fitur-fitur terkini menjadikan penggunanya lebih mudah dalam mem-branding diri (personal branding) melalui akun yang dimilikinya. Personal branding merupakan cara memasarkan diri dan karir melalui suatu citra yang dibentuk untuk khalayak umum. Citra tersebut kemudian dapat dipresentasikan melalui beberapa jalur seperti misalnya melalui media sosial maupun secara langsung. Dengan memberikan gambaran yang baik, maka dapat memberikan keuntungan secara dua arah. Pelaku branding bisa membuat dirinya lebih dikenal secara luas, sementara masyarakat mampu percaya dan yakin untuk memilih orang tersebut.

Tujuan seseorang melakukan personal branding tidak hanya untuk dinikmati saat ini saja, seperti berpromosi, tetapi bagaimana cara mereka agar tetap bisa dikenal dan diin- gat oleh masyarakat. Di era digital, sosial media memegang peranan penting sebagai wadah atau media dalam melakukan personal branding. Beberapa sosial media yang sangat sering digunakan masyarakat, seperti Facebook, Twitter, Youtube, Blogger, dan Instagram pun dimanfaatkan oleh penggunanya. Dengan memiliki akun sosial media, masyarakat cukup berinteraksi hanya melalui gadget saja tanpa harus terus menerus melakukan tatap muka secara langsung ke masyarakat.

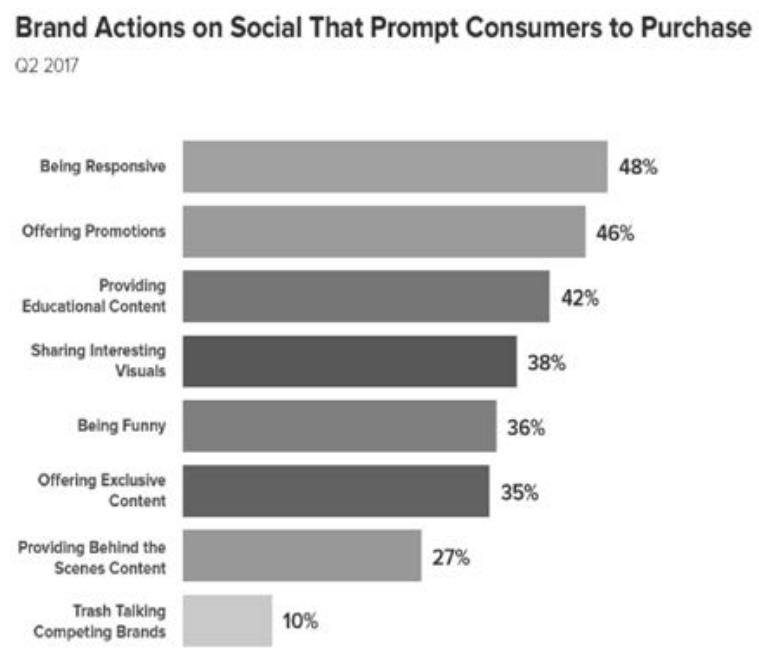
sproutsocial

Gambar 1. Kegiatan di sosial media tahun 2017 (Sumber : https://www.smartinsights. com/social-media-marketing/social-mediastrategy/new-global-social-media-research/)

Pada gambar diatas dijelaskan bahwa kegiatan yang banyak dilakukan melalui sosial media di tahun 2017 lebih banyak pada kegiatan promosi maupun branding. Masyarakat pun banyak yang menjadi responsif dalam kegiatan tersebut. Hal tersebut menjadi alasan kuat mengapa begitu banyak pengguna yang melakukan kegiatan promosi ataupun branding melalui sosial media.

Indonesia sendiri termasuk dalam negara yang masyarakatnya aktif menggunakan sosial media dalam kegiatan sehari-hari meskipun tidak semuanya memanfaatkannya sebagai sarana promosi maupun branding. Dengan mudahnya mengakses internet dan sosial media melalui ponsel, tentunya sangat 
mempermudah masyarakat tanpa harus melalui komputer.

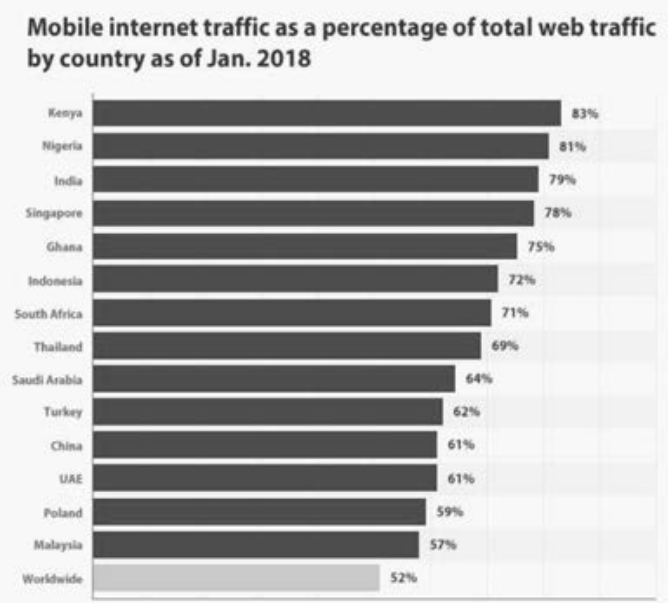

Gambar 2. Tingkat penggunaan internet melalui ponsel di setiap negara pada Januari 2018 (Sumber : https://id.vpnmentor.com/blog/trend-internet-vital/)

Adapun data statistik yang memaparkan beberapa sosial media yang paling banyak digunakan di seluruh dunia. Sosial media tersebut dianggap paling mudah untuk digunakan dan fitur-fitur yang ditawarkan pun sangat menarik dan penuh pembaharuan, sehingga mudah untuk membangun citra perseorangan maupun kelompok dan perusahaan. Sosial media yang kini bukan hanya sekedar media informasi satu arah, tetapi juga sebagai media komunikasi dua arah.

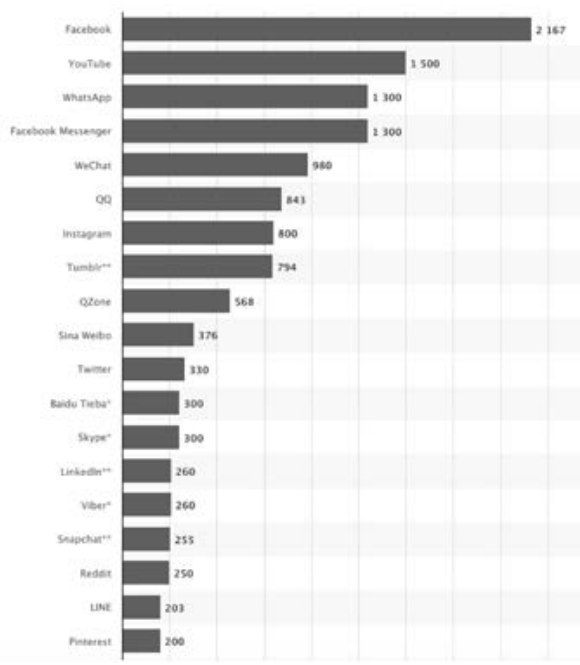

Gambar 3. Penggunaan sosial media yang paling populer akhir tahun 2017 (Sumber : https://www.smartinsights.com/social-media-marketing/social-mediastrategy/new-global-social-media-research/)

Pada data di atas disebutkan bahwa Facebook menempati urutan pertama sebagai sosial me- dia yang memiliki pengguna terbanyak, disusul oleh Youtube dan Instagram. Beberapa sosial media yang akan dijadikan sebagai contoh sarana kreasi dan ekspresi karya seni rupa dan desain adalah Facebook, Youtube, dan Instagram. Ketiga sosial media tersebut akan dibahas contoh pemanfaatan personal branding yang telah dilakukan oleh beberapa penggunanya berdasarkan karya yang termasuk dalam ruang lingkup seni rupa dan desain.

\section{Pembahasan}

Berdasarkan data diatas, maka diambil beberapa contoh pengguna sosial media yang memanfaatkannya sebagai sarana kreasi dan ekspresi karya seni rupa dan desain, yang secara tidak langsung melakukan personal branding sehingga dikenal oleh orang lain. Seperti contoh pertama oleh saudara Raka Jana yang memanfaatkan instagram-nya sebagai sarana untuk menuangkan karya-karyanya.

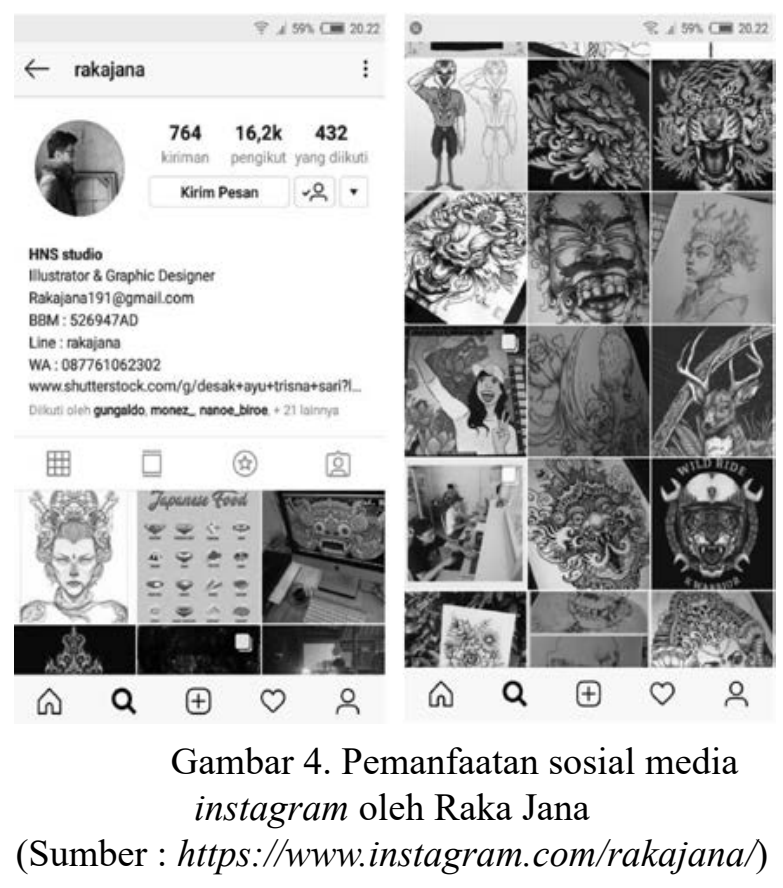

Pada akun instagram milik Raka Jana, terlihat bahwa ia menjadikan feed instagramnya berbicara secara tidak langsung ke audiens. Selain itu pada bagian profil juga terlihat mendeskripsikan pribadinya sendiri, sehingga apabila ada yang tertarik maka akan dengan mudah untuk bisa menghubungi saudara Raka sendiri. Sebuah feed instagram yang disusun dengan baik tentunya memiliki 
nilai lebih tersendiri karena berpengaruh kepada komposisi. Komposisi adalah cara untuk mengatur dan menyusun objek gambar sehingga gambar tampak lebih indah dan menarik. Tidak hanya untuk orang-orang yang mencari jasanya saja, tetapi juga sangat bermanfaat bagi orang-orang yang membutuhkan inspirasi maupun mencari contoh karya ilustrasi milik seseorang yang dianggapnya bagus. Sebuah akun yang akan digunakan untuk bisnis maupun branding yang dimana tujuannya untuk publik, tidak bisa menggunakan mode privat. Oleh karena itu, akun tersebut akan terbuka dan bisa dilihat oleh siapapun. Maka dari itu konten-konten yang diunggah harus sesuai dengan tujuan dibuatnya sebuah akun karena isi dari feed akan dinikmati oleh banyak orang. Adapun akun lain yang memanfaatkan instagram sebagai sarana kreasi dan ekspresi suatu karya adalah akun milik Heydi Paramitha. Heydi sendiri adalah seorang travel blogger. Konten-konten yang diunggah di Instagram-nya adalah foto-foto perjalanan maupun lokasi-lokasi yang menarik dengan gaya masa kini yang biasa disebut instagramable.

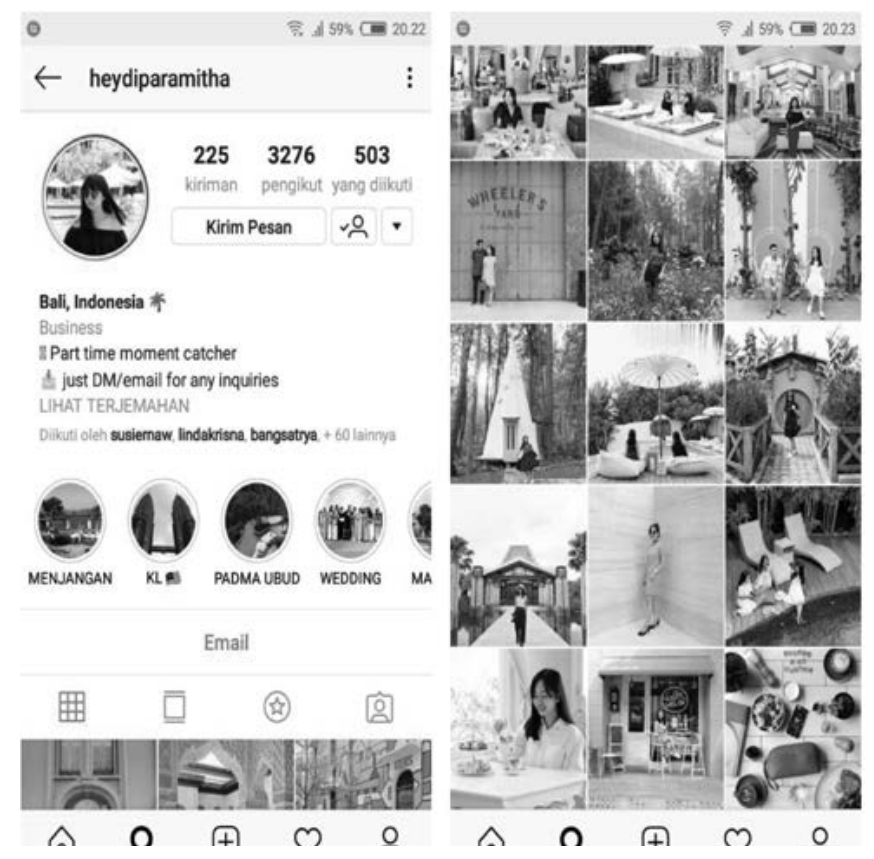

Gambar 5. Pemanfaatan sosial media instagram oleh Heydi Paramitha

(Sumber : https://www.instagram.com/heydiparamitha/)
Pada akun milik Heydi, terlihat ia lebih banyak menggunakan fitur yang disajikan oleh instagram seperti misalnya instastory, highlights dan fitur profil bisnis. Fitur instastory yang hanya bertahan 24 jam saja kini terbantu dengan adanya fitur highlight yang bisa menyimpan story di profil pengguna. Dapat dilihat pada profil milik Heydi pada bagian highlight-nya. Dengan adanya highlight tersebut, orang-orang mampu lebih mudah mencari story yang pernah dibagikan oleh Heydi. Terlebih lagi fitur highlight dapat membagi beberapa grup konten seperti yang terlihat yaitu Menjangan, bagi yang ingin tahu tentang Menjangan; KL bagi yang ingin mengetahui ceritanya di Kuala Lumpur yang mungkin terlewat, dan lainnya.

Pada bagian feed juga terlihat ditata dengan baik, dengan pengambilan gambar yang sesuai. Dalam pengambilan sebuah objek tentunya tidak terlepas pada prinsip komposisi agar terkesan dinamis dan menimbulkan keserasian, dan perlu memperhatikan tentang sudut pemotretan dan pengambilan gambar, serta field of view. Pada akun milik Heydi dapat dilihat kebanyakan fotonya mengambil format vertikal dengan sudut pengambilan low angle dan dengan segi ukuran full shot yaitu pengambilan gambar dengan memberikan porsi background atau foreground lebih banyak. Dengan cara pengambilan tersebut, audiens yang melihat akan ikut menikmati background karena tidak tertutupi oleh wajah traveler.

Adapun contoh pada media lainnya seperti Facebook, juga bisa dimanfaatkan sebagai sarana kreasi dan ekspresi karya. Seperti misalnya akun milik Decky Wira Sanjaya yang seorang cosplayer. Decky sendiri merupakan pengguna yang konsisten mengunggah dan update hal apapun yang terkait dengan cosplay. Untuk menikmati hasil karya cosplay biasanya diabadikan dalam sebuah gambar atau foto, yang tentunya untuk menghasilkan foto yang estetis diperlukan ilmu seni rupa dan desain. 


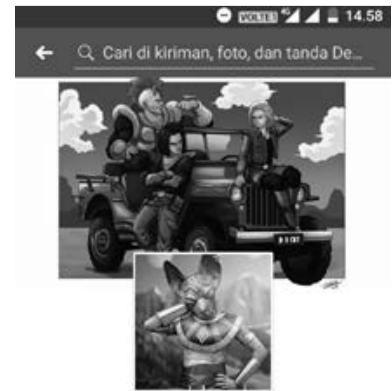

Decky Wira Sanjaya(Daiki)

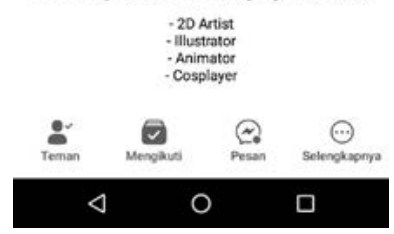

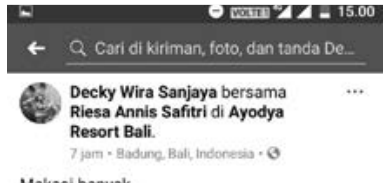

Makasi banyak,

Dapet Juara di Cosplay Competition Bali Japan Matsuri 2018

berawal dari kangen pengen perform dengan

kostum lama

Makasi buat partner tertjinta Riesa Annis Solning mau tak paksa comeback Chikage a a Makasi para helper Yonathan Prasetyo Airy Airyaa.

Photo by Ariya

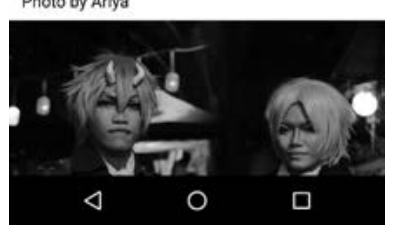

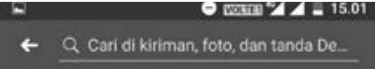

6. Decky Wira Sanjaya Shot on Mi A1

«SHFiguarts \#kamenrider \#kamenriderrx

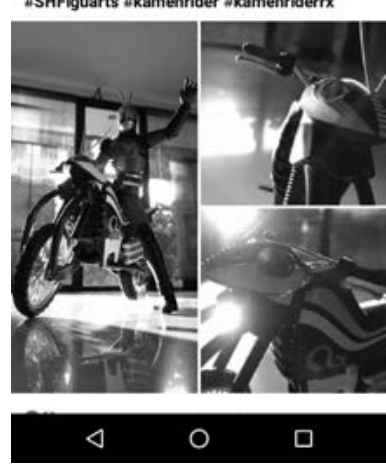

Gambar 6. Pemanfaatan sosial media Facebook oleh Decky Wira Sanjaya (Sumber : https://www.facebook.com/danierudaiki)

Penggunaan Facebook sedikit berbeda dengan Instagram yang lebih banyak bermain dengan gambar. Pada Facebook, pengguna memiliki kesempatan untuk membuat caption atau tulisan yang terletak lebih dulu daripada gambar yang ditampilkan. Oleh karena itu, penyampaian informasi yang dituangkan melalui tulisan atau kata-kata harus mampu mewakili tujuan dan komunikatif. Ilmu copywriting sangat besar pengaruhnya pada sosial media Facebook. Gaya bahasa dan penulisannya pun harus disesuaikan dengan target audiens yang ingin dicapai. Penggunaan Facebook sendiri lebih banyak pemanfaatannya layaknya sebuah diary, yaitu bercerita tentang kegiatan sehari-hari secara konsisten, dengan gaya bahasa dan penulisan serta gambar yang sesuai. Penggunaan gambar atau foto sangat berpengaruh besar terhadap respon audiens dibandingkan dengan kiriman yang hanya berupa tulisan saja, karena gambar mampu menjadi point of view ketika beberapa orang hanya melewati atau scroll pada postingan yang dianggapnya kurang menarik.

Adapun contoh pengguna lainnya yaitu Monez Gusmang. Monez sendiri memang memanfaatkan beberapa sosial medianya sebagai sarana kreasi dan ekspresi karyanya, yang secara tidak langsung mem-branding dirinya sendiri sehingga banyak yang mengenalnya.

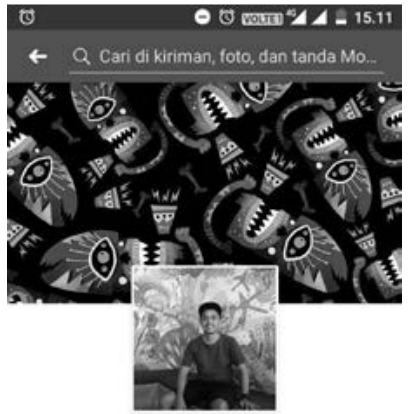

Monez Gusmang

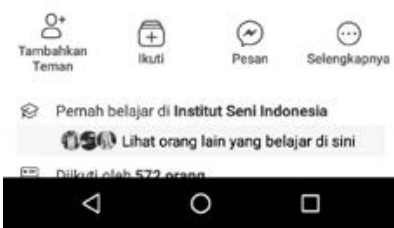

Gambar 7. Pemanfaatan sosial media Facebook oleh Monez

(Sumber : https://www.facebook.com/monez.gusmang)

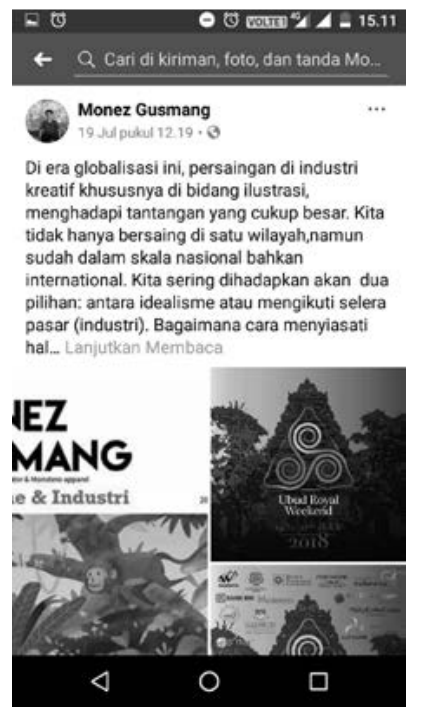

$\square$ 
Konten atau postingan yang diunggah oleh Monez tidak lagi hanya karya saja, tetapi lebih ke informasi untuk banyak orang baik itu kegiatan maupun event workshop dan pameran. Melalui sebuah karya yang baik tentunya akan menghasilkan personal branding yang baik juga.

Selain penggunaan Instagram dan Facebook, berkreasi dan mengekspresikan karya juga bisa melalui media Youtube. Pada youtube sendiri, pengguna bisa mengunggah hasil video mereka dan berbagi kepada banyak orang. Untuk bisa mendapatkan feedback positif tentunya perlu memahami tata cara pengambilan video, durasi, dan isi dari video tersebut. Youtube sendiri memiliki durasi tidak lebih dari 15 menit untuk pengguna yang belum terverifikasi dan maksimal $128 G B$ atau 12 jam untuk pengguna yang telah terverifikasi.

Konten video berbeda dengan gambar atau foto, sehingga penonton akan dihinggapi rasa bosan ketika video yang ditonton terlalu lama, atau tidak sesuai dengan apa yang tertulis pada caption. Mengemas sebuah video tentunya lebih sulit selain bermain dengan potongan scene yang tepat, besar atau kecilnya suara yang dihasilkan, ekspresi, dan cara pengambilan gambar. Berikut salah satu contoh pengguna Youtube yang sering berbagi video secara konsisten dengan isi yang tidak membuat penontonnya bosan dan memberi rasa penasaran akan kelanjutan ceritanya, yaitu akun Youtube milik Arief Muhammad.
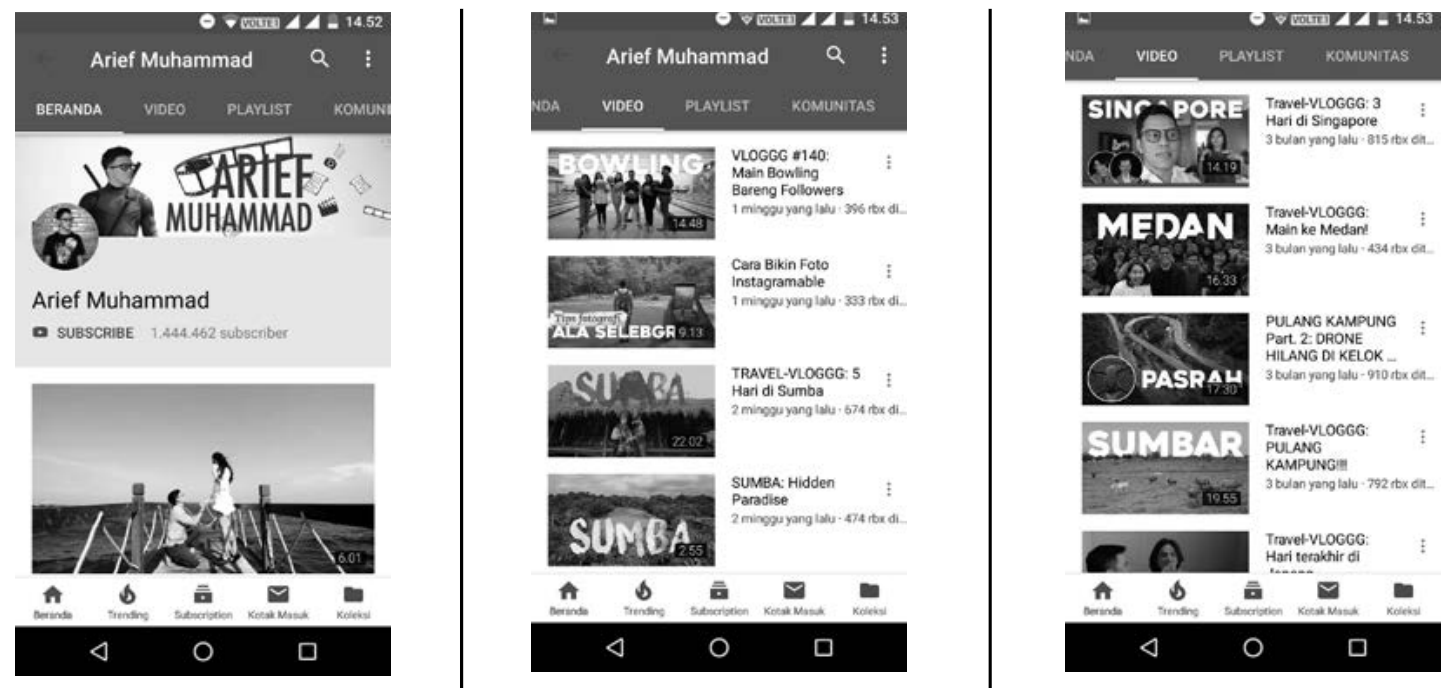

Gambar 8. Pemanfaatan media sosial Youtube oleh Arief Muhammad

(Sumber : https://www.youtube.com/user/AriefMuhammaddd)

Akun youtube milik Arief awalnya adalah sebuah daily vlog, berhubung Arief memiliki hobi traveling yang dibarengi dengan pekerjaannya maka pada akhirnya banyak membuat video tentang trip atau traveling. Akun youtube-nya memiliki 1,4 jutaan subscribers atau pengikut sehingga banyak sekali respon yang didapatkan dalam satu kontennya. Dalam pengemasan videonya pun terbilang informatif dan komunikatif sehingga mampu berkomunikasi secara tidak langsung kepada penonton. Salah satu hal yang berpengaruh selama pemutaran video adalah latar belakang suara/musik atau backsound. Dengan penggunaan musik dan suara yang sesuai maka mampu menggambarkan situasi yang ada dalam video baik itu situasi senang, sedih maupun takut.

Konsistensinya dalam meng-upload travel $v$ log menjadikan pengikutnya memiliki rasa penasaran dan tidak sabar dengan perjalanan selanjutnya. Sehingga dapat dikatakan Youtube yang awalnya hanya sebagai sarana kreasi dan ekspresi kini menjadi media terbentuknya personal branding bagi pemiliki akun sendiri. 


\section{SIMPULAN}

Berdasarkan pemaparan diatas dapat ditarik kesimpulan bahwa, sosial media di era digital sangat besar pengaruhnya untuk kehidupan sehari-hari. Orang-orang dapat dengan mudah berkresi dan mengekspresikan hasil karyanya melalui beberapa sosial media, menemukan dan mengeksplorasi halhal baru yang sesuai dengan minat dan kesukaannya masing-masing. Sosial media juga berpengaruh sebagai sarana pendekatan dari satu orang ke orang lainnya tanpa harus saling bertatap wajah. Sosial media tidak lagi hanya sebagai sarana informasi tetapi juga sebagai media komunikasi dua arah. Sosial media juga mampu menjadi sarana personal branding bagi penggunanya sehingga dikenal oleh masyarakat luas, seperti pemanfaatan instagram oleh Raka Jana dan Heydi, pemanfaatan facebook oleh Decky dan Monez hingga pemanfaatan Youtube oleh Arief Muhammad. Semua media sosial yang digunakan tentunya memiliki fungsi yang sama dengan fitur yang berbeda-beda. Pemanfaatan fitur sangat berpengaruh terhadap keberhasilan respon dari audiens. Oleh sebab itu, penggunaan fitur pada sosial media hendaknya digunakan secara baik dan sesuai dengan fungsinya. Ilmuilmu dalam seni rupa dan desain juga sangat berpengaruh terhadap konten yang dihasilkan oleh penggunanya. Dengan demikian maka konten yang diunggah bukanlah konten sembarangan dan apa adanya, tetapi konten yang memang memiliki nilai dan kualitas sehingga mampu menarik audiens.

Adapun yang harus diperhatikan dari kemudahan-kemudahan yang diberikan oleh sosial media, maka perlu diingat bahwa dengan kebebasan yang ada tentunya mempermudah orang lain untuk mendapatkan contoh dari hasil karya pengguna sosial media. Pembajakan kemungkinan besar akan terjadi dan salah satu antisipasi awal yang bisa dilakukan adalah dengan mengunggah menggunakan resolusi kecil, terutama untuk konten gambar atau foto. Diharapkan dengan adanya kemudahan di era digital, terutama dengan melonjaknya penggunaan sosial me- dia, pengguna mampu menggunakan sosial media dengan bijak dan baik, dan bagi pelaku yang bergerak di bidang seni dan desain yang telah menggunakan sosial media diharapkan untuk terus mencoba fitur-fitur sosial media yang disajikan dengan beberapa pembaharuan berkala sehingga lebih mudah untuk berkomunikasi dengan audiens.

\section{DAFTAR PUSTAKA}

FSR ISI Yogyakarta. 2007. Irama Visual. Jalasutra, Yogyakarta.

Pujiriyanto. 2005. Desain Grafis Komputer. Andi, Yogyakarta.

Percy, Larry. 2003. Advertising and Brand Equity. Dalam Flemming Hansen \& Lars Bech.

Christensen. 2003. Branding and Advertising. Copenhagen Business School Press. Denmark.

Moriarty, Sandra, Nancy Mitchell \& William Wells. 2011. Advertising. Kencana, Jakarta.

Almantara, Sugik. Oktober 2013. Sejarah Sosial Media dan Perkembangan Sosial Media,. http://sugikshare.blogs pot.com/2013/10/sejarah-sosial-media$\mathrm{d}$ a $\mathrm{n}-\mathrm{p}$ e r k e m b a n g a $\mathrm{n} \mathrm{h} \mathrm{m} 1$ diperoleh 1 Juni 2018.

Bergstrom, Breonna. 2018. How to Build Social Media Branding Guidelines That Will Make Your Brand Memorable, https://coschedule.com/blog/social - media-branding-guidelines/. Diperoleh 20 Juli 2018.

Chaffey, Dave. 28 Maret 2018. Global Social Media research Summary 2018. https://www.smartinsights.com/ social-media-marketing/socialmedia-strategy/new-global-socialmedia-research/) diperoleh 10 Juli 2018.

Fawkes, Gey. 2018. Tren Internet 2018, Statistik dan Fakta di AS dan Seluruh Dunia. h t t p s : / / i d. v p n m e n t o r. com/blog/trend-internet-vital/ Diperoleh 13 Juli 2018.

Lacy, Kyle. 17 November 2010. The Power of Personal Branding, http://kylelacy.com/ the-power-of-personal-branding/. Diperoleh 20 Juli 2018. 